\title{
Транспортные процессы с участием атомов углерода между поверхностью и объемом родия при образовании и разрушении графена
}

\author{
(C) Е.В. Рутьков, Е.Ю. Афанасьева, Н.Р. Галль \\ Физико-технический институт им. А.Ф. Иоффе Российской академии наук, \\ 194021 Санкт-Петербург, Россия \\ E-mail: rutkov@ms.ioffe.ru
}

Поступила в Редакцию 30 января 2020 г.

В окончательной редакции 10 февраля 2020 г.

Принята к публикации 10 февраля 2020 г.

Исследованы равновесные транспортные процессы с участием атомов углерода между поверхностью родиевого образца и его объемом, определяющие кинетику фазового перехода, вызывающего образование и разрушение графена. Найдена разность энергий активации растворения атомов углерода $E_{s} 1$ и энергии активации выделения $E_{1 s}$ из объема на поверхность $\Delta E=0.7$ эВ. Определена температурная зависимость критического покрытия $N_{e q}=N_{e q}(T)$ в слое хемосорбированного углерода, при котором происходит двумерный фазовый переход и образуются островки графена: например, при $T=1800 \mathrm{~K} N_{e q}=7.7 \cdot 10^{14} \mathrm{~cm}^{-2}$, а при $T=1000 \mathrm{~K} N_{e q}=3.1 \cdot 10^{14} \mathrm{~cm}^{-2}$.

Ключевые слова: графен, углерод, фазовый переход, родий.

DOI: $10.21883 /$ FTP.2020.06.49384.9360

\section{1. Введение}

Родиевые образцы часто используют для образования графеновых пленок и для изучения различных свойств таких пленок, в частности, при изучении процессов интеркалирования графена различными атомами и молекулами с целью создания изолирующего слоя между графеном и металлом [1-8].

В наших работах [4,9-11] подробно изучена физическая картина при напылении углерода на поверхность $\mathrm{Rh}(111)$. Показано, что вначале углерод активно растворяется в объеме нагретого металла и после достижения предельной растворимости на поверхности происходит фазовый переход первого рода типа конденсации и образуются графеновые островки. При дальнейшем поступлении атомов углерода островки растут по площади, сливаются и образуется сплошной слой графена, однородный по работе выхода с $е \varphi=4.3$ эВ [4]. Ранее мы определили предельную растворимость углерода в родии $[9,11]$, а с учетом контроля за поверхностной концентрацией углерода, например, методом электронной оже-спектроскопии (ЭОС), имелась возможность следить за полным балансом углерода между поверхностью и объемом образца в абсолютных концентрациях.

Цель настоящей работы - во-первых, определение энергетических параметров, отвечающих за транспортные процессы между поверхностью и объемом родия с участием атомов углерода в условиях равновесия при образовании и разрушении графена. Во-вторых, определение важнейшей характеристики фазового перехода - равновесной поверхностной концентрации углерода, при которой зарождаются островки графена - аналог давления насыщенного пара в системе жидкость-пар.

\section{2. Методика эксперимента}

Опыты проводились в сверхвысоковакуумном ожеспектрометре высокого разрешения $(\Delta E / E \leq 0.1 \%)$ с регистрацией оже-спектров непосредственно при высоких температурах образца, что имело принципиальное значение, так как изменение температуры приводило к резкому изменению физической картины в слое углерода на поверхности [9-11]. Для абсолютной калибровки интенсивности оже-сигнала углерода рядом с рабочей родиевой лентой помещали иридиевую ленту с одним слоем графена с $N_{\mathrm{C}}=N_{\mathrm{Cm}}=3.86 \cdot 10^{15} \mathrm{~cm}^{-2}$.

В установке имелся специальный модуль для применения метода термоэлектронной эмиссии и поверхностной ионизации (ТЭПИ) [12,13]. Относительную площадь островков графена определяли разработанным нами способом - зондированием поверхности потоком молекул $\mathrm{CsCl}$ : на участках поверхности, свободных от островков, происходит диссоциация молекул и атом цезия десорбируется только в виде иона $\mathrm{Cs}^{+}$, что легко регистрируется, в то же время на островках графена диссоциация отсутствует $[9,12]$. Поэтому измеряемый ток $I^{+}$ионов цезия позволяет определить относительную площадь островков графена $s_{0}$ : $s_{0}=\left(1-I^{+} / I_{0}^{+}\right)$, где $I_{0}^{+}-$ионный ток с чистой поверхности родия.

Образцами служили тонкие родиевые ленты размерами $50 \times 1 \times 0.02$ мм. Текстурированные и очищенные 
высокотемпературным прогревом при $1800 \mathrm{~K}$ в атмосфере кислорода $\left(P\left(\mathrm{O}_{2}\right) \approx 1 \cdot 10^{-5} \mathrm{Topp}\right)$ образцы имели поверхность грани (111) с работой выхода $е \varphi=5.0$ эВ. Поверхность была однородна по работе выхода.

Для науглероживания родия использовали напуск паров бензола $\left(\mathrm{C}_{6} \mathrm{H}_{6}\right)$, что автоматически обеспечивало симметрию поступления углерода с двух сторон ленты [1-4].

Температура ленты определялась оптическим микропирометром в диапазоне $1100-1800 \mathrm{~K}$, а в области более низких температур - путем линейной экстраполяции зависимости температуры от тока накала ленты к комнатной температуре. Однородность температуры в средней части ленты ( $\sim 40$ мм) была не хуже $\pm 5 \mathrm{~K}$. Анализируемый участок ленты в ее середине составлял $\sim 5$ мм.

\section{3. Экспериментальные результаты}

\section{1. Транспортные процессы поверхность-объем в системе Rh-углерод}

На рис. 1 показана зависимость интенсивности ожесигнала углерода $I_{\mathrm{C}}$ от температуры науглероженного при $T_{\mathrm{c}}=1200 \mathrm{~K}$ родия. Оже-сигнал регистрировался с нагретого образца. Как показано в наших работах $[4,9]$, при $T>T_{\mathrm{c}}$ на поверхности родия присутствует только хемосорбированный углеродный „газ“, находящийся в равновесии с атомами углерода, растворенными в объеме родия.

При $T<1200 \mathrm{~K}$ интенсивность оже-сигнала родия резко возрастает - на поверхности в углеродном слое происходит двумерный фазовый переход и образуются графеновые островки, скорость роста которых с понижением температуры в области $1000-1200 \mathrm{~K}$ увеличивается (рис. 1). При образовании островков графена резко увеличивается и термоэлектронная эмиссия с образца, так как работа выхода островков графена

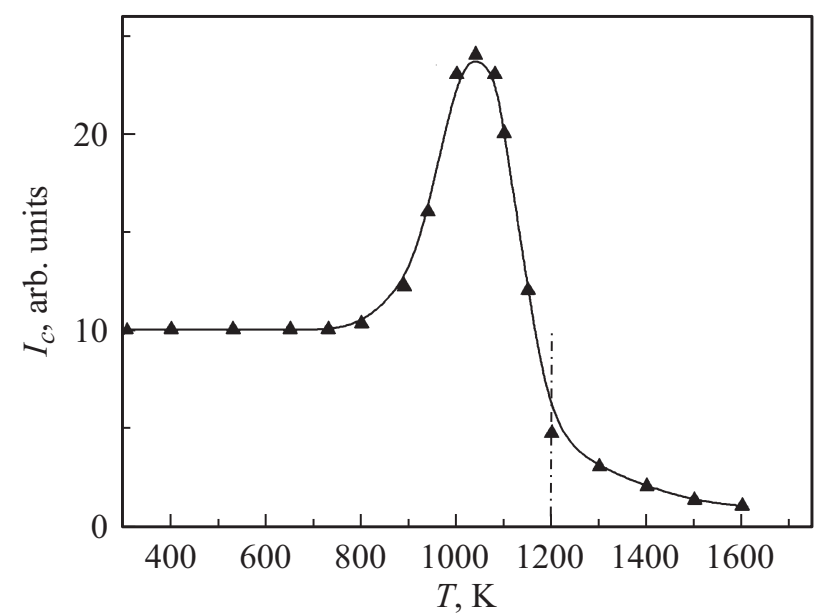

Рис. 1. Зависимость оже-сигнала углерода от температуры науглероженного при $T_{\mathrm{c}}=1200 \mathrm{~K}$ родиевого образца.
4.3 эВ, а работа выхода родия с углеродным „газом“ на поверхности 5.0 эВ. Поэтому термоэлектронная эмиссия „чувствует“ зарождение островков графена, имеющих площадь $\sim 0.01 \%$. При $T<800 \mathrm{~K}$ объемная диффузия углерода в родии замораживается и рост островков графена прекращается. Подставка $I_{\mathrm{C}}=10$ ед. при $T<800 \mathrm{~K}$ связана с неизбежным быстрым выделением углерода из объема ленты при ее охлаждении, когда температура уменьшается от высоких значений до низких.

Рассмотрим экспериментальные данные в области $1200-1600 \mathrm{~K}$ (рис. 1). Воспользуемся физической моделью и уравнениями, описывающими транспортные процессы с участием углерода между поверхностью и объемом образца, приведенными в работах $[9,12]$ :

$$
\begin{aligned}
& v_{1}=N_{s} C \exp \left(-E_{s 1} / k T\right), \\
& v_{2}=N_{1} D \exp \left(-E_{1 s} / k T\right),
\end{aligned}
$$

где $v_{1}$ и $v_{2}$ - потоки растворения и выделения, $N_{s}-$ концентрация атомов углерода на поверхности, $N_{1}-$ концентрация диффундирующих атомов в примыкающей к поверхности плоскости междоузлий, $C$ и $D-$ соответствующие предэкспоненциальные множители, $E_{s 1}$ энергия активации растворения, $E_{1 s}-$ энергия активации выделения.

Опыты показывают, что для систем металл-углерод характерно, когда $E_{s 1}>E_{1 s}$. Например, в работе [14] изучали растворение углерода в монокристалле $\mathrm{W}(100)$ и показали, что $E_{s 1}=5.0$ эВ, что намного превышает энергию активации объемной диффузии равную $E_{\text {dif }}=2.56$ эВ. В работе [15] энергия растворения углерода в $\mathrm{Mo}(100) E_{s 1}=3.9$ эВ (малые покрытия), хотя энергия активации объемной диффузии $E_{\mathrm{dif}}=1.78$ эВ. Поэтому можно ожидать, что и в нашем случае $E_{s 1} \gg E_{1 s}$ и соответственно при равновесии $N_{s} \gg N_{1}$.

Ранее мы определили предельную растворимость $n_{C}$ (ат\%) углерода в родии [9]. Для нашего опыта на рис. 1 $T_{\mathrm{c}}=1200 \mathrm{~K}$ и $n_{C}=2.3 \cdot 10^{-2}$ aт\%.

Зная толщину ленты, нетрудно подсчитать, что в каждом слое междоузлий будет $N_{1}=2 \cdot 10^{11} \mathrm{aT} \cdot \mathrm{cm}^{-2}$. В то же время калибровка оже-сигнала углерода $I_{\mathrm{C}}$ по отношению к эталону - один слой графена на $\operatorname{Ir}(111)$ с $N_{\mathrm{Cm}}=3.86 \cdot 10^{15} \mathrm{aт} \cdot \mathrm{cm}^{-2}$ дает значение $N_{s}=8 \cdot 10^{14}$ aт $\cdot \mathrm{cm}^{-2}$ при $T_{\mathrm{c}}=1200 \mathrm{~K}$. Столь большая разница $N_{s}$ и $N_{1}$ соответствует тому, что $E_{s 1} \gg E_{1 s}$.

В условиях равновесия $v_{1}=v_{2}$ и систему уравнений (1) можно привести к виду:

$$
\begin{aligned}
N_{s} / N_{1} & =D / C \exp \left[\left(E_{s 1}-E_{1 s}\right) / k T\right] \\
& =D / C \exp (\Delta E / k T) .
\end{aligned}
$$

В наших опытах можно считать, что при изменении температуры общее количество углерода в объеме ленты остается неизменным - добавка углерода за счет его перехода с поверхности в объем металла пренебрежительно мала, т.е. $N_{1}=\mathrm{const} \neq f(T)$. Поэтому из 


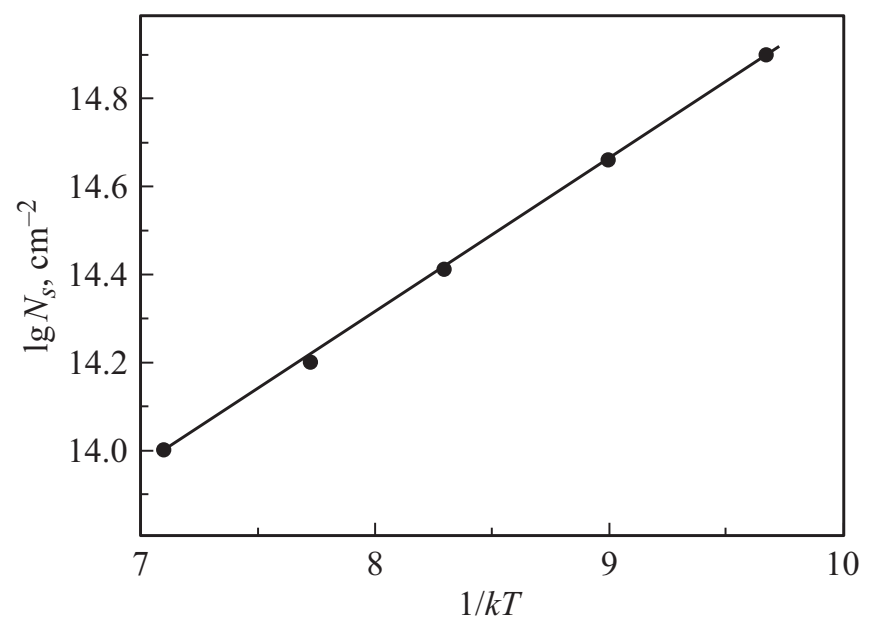

Рис. 2. Зависимость поверхностной концентрации хемосорбированного углерода $N_{s}$ на $\operatorname{Rh}(111)$ в координатах $\lg N_{s}$ от температуры образца в координатах $1 / k T$. Температура науглероживания $T_{\mathrm{c}}=1200 \mathrm{~K}$.

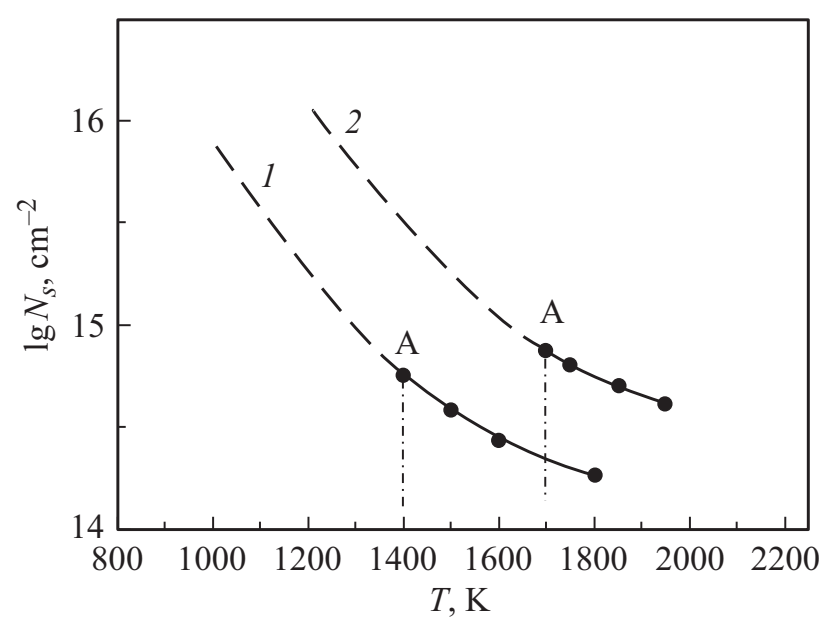

Рис. 3. Зависимость равновесного покрытия хемосорбированным углеродом $\mathrm{Rh}(111)$ от температуры образца для разных температур науглероживания: $1-T_{\mathrm{c}}=1400 \mathrm{~K}, 2-1700 \mathrm{~K}$. Пунктир - данные, рассчитанные по формуле (2).

зависимости $\ln N_{s}=f(1 / k T)$ можно найти $\Delta E$. На рис. 2 представлена эта зависимость (для удобства в координа$\left.\operatorname{Tax} \lg N_{s}\right)$. Наклон графика дает величину $\Delta E=0.7$ эВ, а зная $N_{s}$ и $N_{1}$, можно найти отношение $D / C \approx 1$.

Зная $\Delta E$, можно рассчитать концентрацию поверхностного покрытия при любых температурах, соответствующих активной объемной диффузии $(T>1000 \mathrm{~K})$ при разных температурах науглероживания $T_{\mathrm{c}}$ в условиях равновесия (рис. 3). На этом рисунке показаны экспериментальные кривые и расчетные (пунктир) для двух температур науглероживания $T_{\mathrm{c}}=1400$ и $1700 \mathrm{~K}$.

Можно ожидать, что энергия $E_{1 s}$ будет близка к энергии активации объемной диффузии $E_{\text {dif. }}$ Оценим эту энергию из следующих соображений. Из рис. 1 видно, что при $T<800 \mathrm{~K}$ диффузия атомов углерода по объему резко замораживается. В работе [11] показано, что для системы $\mathrm{Ni}(111)$-углерод объемная диффузия замораживается в близком к родию диапазоне температур 700-800 K. Поскольку для $\mathrm{Ni}(111)$ величина $E_{\mathrm{dif}}=1.5$ эВ $[16,17]$, то и для родия разумно считать, что величина будет близка к 1.5 эВ. В этом случае $E_{s 1}=\Delta E+E_{\mathrm{dif}} \approx 2.3$ эВ.

\section{2. Определение критического покрытия $N_{e q}$, соответствующего двумерному фазовому переходу в системе Rh-углерод}

Достижение предельной растворимости углерода в родии фиксируется по образованию новой фазы углерода на поверхности - островков графена, когда на поверхности достигается критическое покрытие $N_{e q}$. Из работы [9]:

$$
\ln \left[n_{C}(\mathrm{aT} \%)\right]=5.06-10508 / T .
$$

Тогда концентрация углерода $N_{1}$ в каждой плоскости междоузлий площадью $1 \mathrm{~cm}^{2}$, в том числе и в плоскости, примыкающей к поверхности:

$$
N_{1}=0.01 N_{\mathrm{Rh}} \exp (5.06-10580 / T),
$$

где $N_{\mathrm{Rh}}=2 \cdot 10^{15}$ ат $\cdot \mathrm{cm}^{-2}-$ концентрация атомов родия в одной атомной плоскости для площади $1 \mathrm{~cm}^{2}$.

Используя уравнение (2), можно найти критическое покрытие $N_{e q}$, ответственное за фазовый переход в слое углерода:

$$
\begin{aligned}
N_{e q} & =N_{1} D / C \exp (\Delta E / k T) \\
& =0.01 N_{\mathrm{Rh}} D / C \exp (\Delta E / k T+5.06-10580 / T) .
\end{aligned}
$$

Пусть $T=1600 \mathrm{~K}, \Delta E=0.7$ эВ, $D \approx C$ (см. выше). Тогда $N_{e q}=7.3 \cdot 10^{14} \mathrm{aT} \cdot \mathrm{cm}^{-2}$, что отлично совпадает

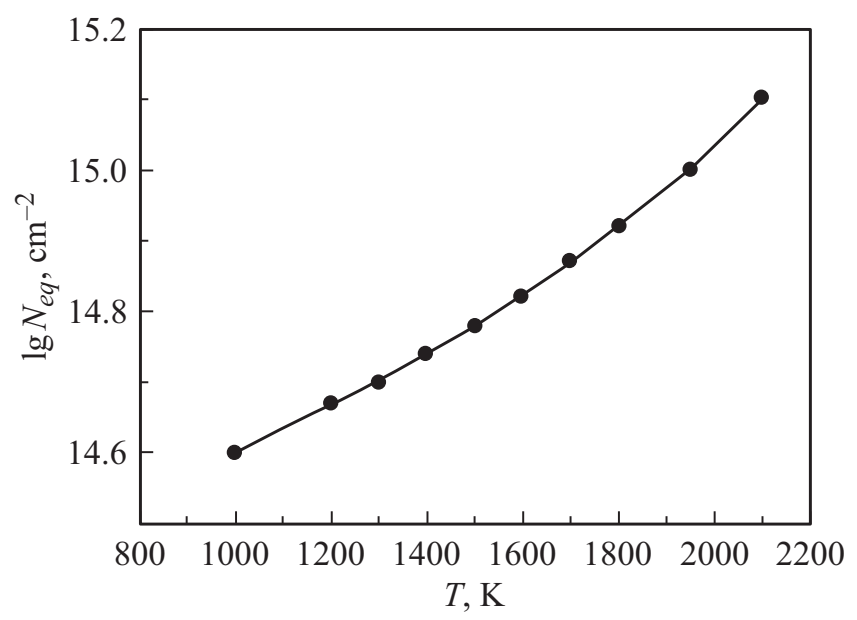

Рис. 4. Зависимость критического покрытия хемосорбированным углеродом от температуры подложки, соответствующего фазовому переходу, приводящему к образованию графена на $\mathrm{Rh}(111)$. 
с величиной, определенной прямым методом ЭОС для данной температуры. На графике рис. 4 приведены расчетные данные по формуле (5).

Видно, что величина $N_{e q}$ слабо меняется с температурой, например, при $T=1800 \mathrm{~K} N_{e q} \approx 7.7 \cdot 10^{14} \mathrm{~cm}^{-2}$, a при $T=1000 \mathrm{~K} N_{e q} \approx 3.1 \cdot 10^{14} \mathrm{~cm}^{-2}$.

\section{3. Кинетика роста графеновых островков на родии}

На рис. 5 показана кинетика роста относительной площади островков графена на $\mathrm{Rh}(111)$ в зависимости от температуры образца для $T_{\mathrm{c}}=1400 \mathrm{~K}$. Видно, что скорость роста существенно увеличивается при понижении температуры. Например, если для образования $s_{0}=50 \%$ при $T_{1}=1365 \mathrm{~K}$ требуется время $t_{1}=40 \mathrm{c}$, то для $T_{2}=1255 \mathrm{~K}$ время гораздо меньше $t_{2}=2 \mathrm{c}$. В этих опытах температура резко понижалась от $1800 \mathrm{~K}$ до необходимой в опыте.

Основным вкладом в скорость роста островков является уменьшение критического поверхностного покрытия с понижением температуры и, как следствие, появление множества ,лишних“, сверх критического покрытия, атомов углерода, которые охотно встраиваются в графеновые островки, резко увеличивая их площадь, - кривая 1 для $T_{\mathrm{c}}=1400 \mathrm{~K}$ на рис. 3. Точка „A“ на этом рисунке соответствует фазовому переходу и образованию островков графена. Также показано, что с увеличением $T_{\mathrm{c}}$, т.е. с увеличением концентрации растворенного углерода, скорость роста островков должна существенно увеличиться. Например, для образования $s_{0}=50 \%$ для $T_{\mathrm{c}}=1400 \mathrm{~K}$ и $T=1100 \mathrm{~K}$ требуется время несколько секунд, то для $T_{\mathrm{c}}=1200 \mathrm{~K}$ и той же температуре требуется время несколько минут.



Рис. 5. Зависимость относительной площади графеновых островков $s_{0}$ от времени экспозиции науглероженного при $T_{\mathrm{c}}=1400 \mathrm{~K}$ родия для разных температур образца $T(\mathrm{~K})$ : $1-1365,2-1340,3-1300,4-1255$.

\section{4. Заключение}

Таким образом, транспорт углерода между поверхностью и объемом металла действительно обеспечивает возможность для протекания фазового перехода на поверхности, приводящего к образованию или разрушению графена. Быстрота диффузии углерода в объеме и низкая суммарная концентрация поверхностного углерода по сравнению с его количеством, растворенным в объеме, делают „объемную“ и „поверхностную“ части фазового перехода практически независимыми друг от друга, что резко упрощает его рассмотрение.

\section{Конфликт интересов}

Авторы заявляют, что у них нет конфликта интересов.

\section{Список литературы}

[1] Е.В. Рутьков, Н.Р. Галль. Письма ЖЭТФ, 100 (10), 708 (2014).

[2] Е.В. Рутьков, А.В. Кузьмичев, Н.Р. Галль. Письма ЖЭТФ, 93 (3), 166 (2011).

[3] Е.В. Рутьков, Н.Р. Галль. ФТП, 52 (9), 111 (2018).

[4] Е.В. Рутьков, А.В. Кузьмичев, Н.Р. Галль. ФТТ, 53 (5), 1026 (2011).

[5] А.Я. Тонтегоде, Ф.К. Юсифов. ЖТФ, 43, 1045 (1973).

[6] N. Sicot, P. Leicht, A. Zusan, S. Bouvron, O. Zander, M. Weser, Yu.S. Dedkov, K. Horn, M. Fonin. ACS nano, 6 (1), 151 (2012). doi:10.1021/nn203169j

[7] K. Gotterbarm, W. Zhao, O. Höfert, C. Gleichweit, C. Papp, H.-P. Steinrück. Phys. Chem. Chem. Phys., 15, 19625 (2013).

[8] C. Romero-Muniz, A. Martín-Recio, P. Pou, J.M. GomezRodríguez, Ruben Perez. Carbon, 101, 129 (2016).

[9] E.V. Rut'kov, N.R. Gall. Physics and Applications of Graphene - Experiments (Rijeka, Croatia, In Tech., 2011) c. 209.

[10] N.R. Gall, E.V. Rut'kov, A.Ya. Tontegode. Int. J. Mod. Phys., 11, 1865 (1997).

[11] Н.Р. Галль, Е.В. Рутьков. Физика поверхности твердых тел. Графен и графит на поверхности твердых тел. Учеб. пособие (СПб., Изд-во Политехн. ун-та, 2013) с. 160.

[12] A.Ya. Tontegode. Prog. Surf. Sci., 38, 201 (1991).

[13] Э.Я. Зандберг, Н.И. Ионов. Поверхностная ионизация (М., Наука, 1969).

[14] K.J. Rowlings, S.D. Foulias, B.J. Hopkins. Surf. Sci., 109, 513 (1981).

[15] Е.В. Рутьков, А.Я. Тонтегоде, М.М. Усуфов. Изв. РАН. Сер. физ., 58(10), 102 (1994).

[16] E. Fromm, E. Gebhardt. Gase und Kohlenstoff in Metallen (Berlin, Springer Verlag, 1976).

[17] Ф.А. Шанк. Структура бинарных сплавов (М., Металлургия, 1973).

Редактор Г.А. Оганесян 


\section{Atomic Carbon Transport between Rh Surface and Bulk in Graphene Formation and Destruction}

\section{E.V. Rut'kov, E.Y. Afanas'eva, N.R. Gall}

loffe Institute,

194021 St. Petersburg, Russia

Abstract Equilibrium transport of atomic carbon between $\mathrm{Rh}$ surface and bulk has been studied. This transport controls the kinetics of the phase transition resulting in graphene growth or destruction. The difference $\Delta E=0.7 \mathrm{eV}$ has been measured between the activation energy of atomic carbon dissolution $E_{1 s}$ and that of its segregation from the bulk to the surface $E_{1 s}$. The temperature dependence of chemisorbed carbon critical cover $N_{e q}=N_{e q}(T)$ has been measured, that is the cover when 2D phase transition takes place and graphene islands start to grow. E.g., $N_{e q}=7.7 \cdot 10^{14} \mathrm{~cm}^{-2}$ at $T=1800 \mathrm{~K}$, and $N_{e q}=3.1 \cdot 10^{14} \mathrm{~cm}^{-2}$ at $T=1000 \mathrm{~K}$. 